\title{
The Construction and Characterization of Self-Sufficient Lanosterol 14-Demethylase Fusion Proteins Consisting of Yeast CYP51 and Its Reductase
}

\author{
Yutaka Kitahama, ${ }^{a}$ Masashi Nakamura, ${ }^{a}$ Yuzo Yoshida, ${ }^{b}$ and Yuri Aoyama ${ }^{*, a}$ \\ ${ }^{a}$ Department of Bioinformatics, Faculty of Engineering, Soka University; Hachioji, Tokyo 192-8577, Japan: and ${ }^{b}$ School \\ of Pharmaceutical Sciences, Mukogawa Women's University; Nishinomiya, Hyogo 663-8179, Japan. \\ Received November 24, 2008; accepted January 28, 2009; published online January 30, 2009
}

Two forms of a self-sufficient lanosterol 14-demethylase fused enzyme consisting of Saccharomyces cerevisiae CYP51 and $S$. cerevisiae reduced nicotinamide-adenine dinucleotide phospahte (NADPH)-P450 reductase were constructed and characterized. The two forms of fused enzymes, F1 and F2, which had slight differences in the linker regions between their P450 and reductase domains, were expressed in Escherichia coli cells. Both F1 and F2 were purified to homogeneity. The purified preparations of F1 and F2 showed spectral properties of not only P450 but also flavoprotein. F1 and F2 showed lanosterol 14-demethylase activity with kinetic parameters comparable to those obtained with a reconstituted system consisting of $S$. cerevisiae CYP51 and $S$. cerevisiae NADPH$P 450$ reductase. These facts indicate that $F 1$ and $F 2$ are self-sufficient lanosterol 14-demethylases that can catalyze three successive monooxygenations with comparable activity to naturally occurring CYP51. The enzymatic reduction of the CYP51 in F1 and F2 was faster than that of the CYP51 in the reconstituted system. The results of dilution experiments suggested that the electron transfer from the reductase domain to the CYP51 domain in F1 and F2 occurred both intra- and intermolecularly. Two fused self-sufficient lanosterol 14-demethylases were successfully constructed. This is the first example of the purified preparation of an artificial self-sufficient $\mathbf{P 4 5 0}$ monooxygenase that catalyzes the oxidative cleavage of $\mathrm{C}-\mathrm{C}$ bond via three successive monooxygenations.

Key words CYP51; sterol 14-demethylase; lanosterol 14-demethylation; fusion P450; yeast P450

Cytochrome P450 (P450) is a group of heme-protein monooxygenases that catalyze the oxidation of a wide variety of organic compounds including steroids, fatty acids, xenobiotics, and so forth. P450 requires two electrons to activate one oxygen molecule in its catalytic cycle, and the electrons are provided from reduced nicotinamide-adenine dinucleotide phospahte (NADPH) or reduced nicotinamide-adenine dinucleotide (NADH) by means of a specific electrontransferring system, such as NADPH-P450 reductase (P450 reductase), cytochrome $b_{5}$ plus NADH-cytochrome $b_{5}$ reductase, or iron-sulfur protein plus its reductase. ${ }^{1)}$ Although most P450 and electron-transferring proteins are independent proteins encoded by different genes, there are a few self-sufficient monooxygenases that contain both P450 and P450 reductase in a single polypeptide chain. A typical example of such a self-sufficient P450 monooxygenase is the long-chain fatty acid hydroxylase $\mathrm{P} 40_{\mathrm{BM}-3}$ of Bacillus megaterium. ${ }^{2)}$ This monooxygenase consists of P450 (CYP102A1) and P450 reductase domains and shows extremely high molecular turnover $(>1500 / \mathrm{min}){ }^{3)}$ This high activity is considered to be due to efficient intramolecular electron transfer from the reductase domain to the $\mathrm{P} 450$ domain. This has prompted many P450 investigators to construct recombinant self-sufficient drug and steroid metabolizing $\mathrm{P} 450 \mathrm{~s}$ using various mammalian P450 species and P450 reductase, and many recombinant self-sufficient P450 monooxygenases have been reported. ${ }^{4}{ }^{12}$ ) These studies indicate that a self-sufficient artificial P450 monooxygenase can be constructed by joining P450 and P450 reductase by protein engineering.

Some specific P450 species such as CYP19 and CYP51 catalyze oxidative cleavage of $\mathrm{C}-\mathrm{C}$ bond through three successive monooxygenation reactions, ${ }^{13)}$ and it would be interesting to construct a self-sufficient $\mathrm{C}-\mathrm{C}$ bond-cleaving P450. Sterol 14-demethylase P450 (CYP51) is a unique P450 that is widely distributed among five biological kingdoms as a conserved P450 species, ${ }^{14)}$ and a fusion protein consisting of CYP51 and an iron-sulfur protein that displays sterol 14demethylase activity in the presence of ferredoxin reductase has been found in Methylococcus capsulatus. ${ }^{15)}$ However, the electron transfer system to eukaryotic CYP51 is different. Eukaryotic CYP51 receives electrons from P450 reductase, although the bacterial enzyme receives electrons via an electron-transfer system consisting of an iron-sulfur protein and a flavoprotein. The authors will attempt to construct a selfsufficient lanosterol 14-demethylase fusion protein by using yeast CYP51 and P450 reductase. This paper reports the construction of two kinds of recombinant self-sufficient lanosterol 14-demethylase and their molecular and catalytic properties.

\section{MATERIALS AND METHODS}

Materials The cDNA of Saccharomyces cerevisiae CYP51 was prepared by polymerase chain reaction (PCR) from genomic DNA of $S$. cerevisiae. The cDNA of $S$. cerevisiae P450 reductase was provided by Dr. Y. Yabusaki of Sumitomo Chemical Co., Ltd., Takarazuka. An NdeI-HindIII fragment containing the open reading frame (ORF) of $S$. cerevisiae CYP51 cDNA or the ORF of modified S. cerevisiae CYP51 (yCYP51m) cDNA was cloned with pBluescript $\mathrm{KS}^{-}$. An NdeI-HindIII fragment containing the ORF of $S$. cerevisiae $\mathrm{P} 450$ reductase cDNA was also cloned with pBluescript vector. The expression plasmid vector $\mathrm{pCWori}^{+}$ was a generous gift from Dr. M. R. Waterman of Vanderbilt University.

All enzymes used in the DNA recombination were purchased from TOYOBO (Osaka) and Takara Bio (Shiga). The primers for PCR and oligonucleotides for the linker region 
F1 (1182aa)

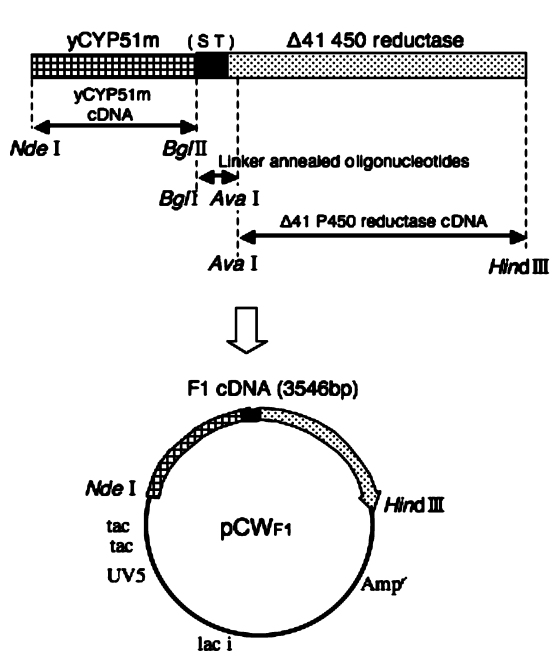

F2 (1179aa)
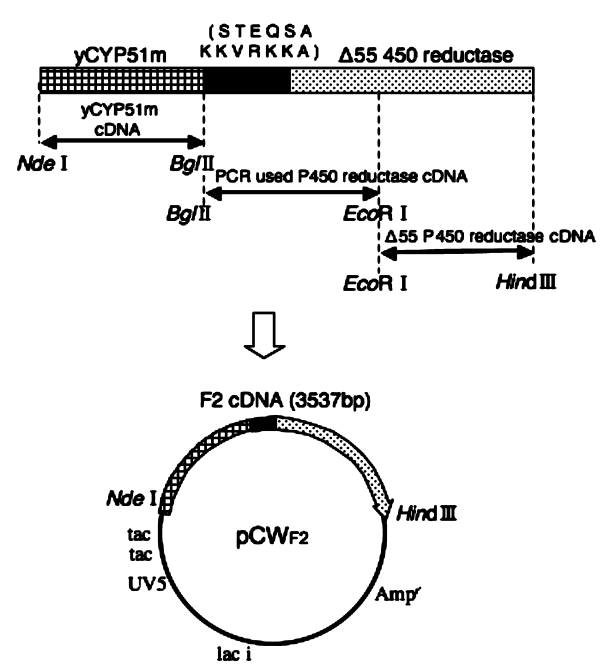

Fig. 1. Construction of Expression Vectors

Two expression vectors, $\mathrm{pCW}_{\mathrm{F} 1}$ and $\mathrm{pCW}_{\mathrm{F} 2}$, were constructed to express the fused self-sufficient sterol 14-demethylases, $\mathrm{F} 1$ and $\mathrm{F} 2$, respectively. Detailed construction strategies were described in Materials and Methods.

between CYP51 and P450 reductase were prepared by BEX (Tokyo). The other chemicals, biochemicals, and enzymes used in this study were guaranteed reagents obtained from commercial sources.

Expression and Preparation of Fusion Protein of $S$. cerevisiae CYP51 in the Membrane Fraction of Escherichia coli The strategy for constructing the expression vector for the fusion proteins containing CYP51 and P450 reductase is shown in Fig. 1, where yCYP51m is a modified yeast $\mathrm{P} 450$ with a modified N-terminal (M-A-L-L-L-A-V-F) for efficient expression in $E$. coli and $\Delta 41$ P450 reductase and $\Delta 55 \mathrm{P} 450$ reductase represent $\mathrm{N}$-terminal truncated (41 amino acids and 55 amino acids, respectively) yeast $\mathrm{P} 450$ reductases. The first fusion protein CYP51 (called F1) consisted of yCYP51m, a linker region containing the amino acid sequence $\mathrm{S}-\mathrm{T}$, and $\Delta 41 \mathrm{P} 450$ reductase. The other fusion protein CYP51 (called F2) consisted of yCYP51m, a linker region containing the amino acid sequence S-T-E-Q-S-A-K$\mathrm{K}-\mathrm{V}-\mathrm{R}-\mathrm{K}-\mathrm{K}-\mathrm{A}$, and $\Delta 55 \mathrm{P} 450$ reductase. The expression vector $\left(\mathrm{pCW}_{\mathrm{F} 1}\right)$ for $\mathrm{F} 1$ was constructed by inserting the $N d e \mathrm{I}-B g l \mathrm{II}$ fragment of yCYP51m cDNA, the BglII-AvaI fragment of the linker, and the AvaI-HindIII fragment of $\Delta 41$ P450 reductase cDNA into the NdeI-HindIII site of $\mathrm{pCWori}^{+}$. The expression vector $\left(\mathrm{pCW}_{\mathrm{F} 2}\right)$ for $\mathrm{F} 2$ was constructed by inserting the NdeI-BglII fragment of yCYP $51 \mathrm{~m}$ cDNA, the $B g l \mathrm{II}-E c o$ RI fragment of the linker, the N-terminal part of $\Delta 55 \mathrm{P} 450$ reductase prepared below, and the EcoRI-HindIII fragment of the C-terminal part of $\Delta 55 \mathrm{P} 450$ reductase cDNA into the $\mathrm{NdeI}-\mathrm{HindIII}$ site of $\mathrm{pCWori}{ }^{+}$. The $B g l \mathrm{II}-E c o \mathrm{RI}$ fragment was prepared by PCR with $S$. cerevisiae $\mathrm{P} 450$ reductase $\mathrm{CDNA}$ as the template and sense $\left(5^{\prime}\right.$ ccagatctccactgaacagtctgctaaaaaagtacgcaaaaaggcagaaaacaacaagaac- $\left.3^{\prime}\right)$ and antisense $\left(5^{\prime}\right.$-atgtaatcttcgtctgtagt- $\left.3^{\prime}\right)$ primers. The expression of $\mathrm{pCW}_{\mathrm{F} 1}$ and $\mathrm{pCW}_{\mathrm{F} 2}$ in the $E$. coli cells was carried out as described previously. ${ }^{16)}$ The expression vectors of yCYP51m and S. cerevisiae P450 reductase were constructed by inserting the fragments containing their ORF regions into the NdeI-HindIII site of $\mathrm{pCWori}^{+}$and were expressed in E. coli cells.
Purification of Fused CYP51s from the Membrane Fraction of $\boldsymbol{E}$. coli All manipulations were carried out at $2-4{ }^{\circ} \mathrm{C}$. The membrane fraction of $E$. coli cells containing F1 or F2 was suspended in $20 \mathrm{~mm}$ potassium phosphate buffer, $\mathrm{pH}$ 7.5, containing 0.5 mm EDTA, $0.5 \mathrm{~mm}$ DTT, 20\% glycerol, $1 \mu \mathrm{m}$ FAD, $1 \mu \mathrm{M}$ FMN, 1 mM phenylmethylsulfonyl fluoride (PMSF), and $1 \mu \mathrm{g} / \mathrm{ml}$ pepstatin to give a protein concentration of 3-4 mg/ml. Emulgen 913 (Kao, Tokyo) was added to the suspension to give a concentration of $1.0 \%$, and the suspension was gently stirred for $40 \mathrm{~min}$. The suspension was centrifuged at $146000 \times \boldsymbol{g}$ for $2 \mathrm{~h}$, and the supernatant was applied to a DE52 column (Whatman) equilibrated with $20 \mathrm{~mm}$ potassium phosphate buffer, $\mathrm{pH} 7.5$, containing $0.5 \mathrm{~mm}$ EDTA, $0.5 \mathrm{~mm}$ DTT, 20\% glycerol, $1 \mu \mathrm{M} \mathrm{FAD,} 1 \mu \mathrm{M}$ FMN, and $0.1 \%$ Emulgen 913 (Buffer A). The column was washed with Buffer A and eluted with a 0 to $0.35 \mathrm{~m}$ concentration gradient of $\mathrm{KCl}$ in Buffer $\mathrm{A}$. The fractions containing F1 or F2 were pooled and applied to a column of $2^{\prime} 5^{\prime}$-ADP Sepharose 4B (Pharmacia Biotech: GE Healthcare Bioscience) equilibrated with Buffer A containing $0.15 \mathrm{M} \mathrm{KCl}$. The column was washed with the equilibration buffer and the adsorbed F1 or F2 was eluted with the equilibration buffer plus $1 \mathrm{~mm} \mathrm{NADP}^{+}$. The F1 or F2 preparation eluted from the column was dialyzed overnight against buffer A. To remove Emulgen 913 from the F1 or F2 preparation, column chromatography with Q Sepharose (Pharmacia Biotech: GE Healthcare Bioscience) was carried out with Buffer A without Emulgen 913.

Purification of yCYP51m and S. cerevisiae P450 Reductase from the Membrane Fraction of $E$. coli Purification of yCYP $51 \mathrm{~m}$ from the membrane fraction of E. coli was carried out as described previously. ${ }^{17)} S$. cerevisiae P450 reductase from the membrane fraction of $E$. coli was purified by the following method. The membrane fraction of E. coli cells containing P450 reductase was suspended in $100 \mathrm{~mm}$ potassium phosphate buffer, $\mathrm{pH} 7.2$, containing $1 \mathrm{~mm}$ EDTA, $1 \mu \mathrm{m} \mathrm{FAD}, 1 \mu \mathrm{M}$ FMN, $0.25 \mathrm{~mm}$ PMSF, and $1 \mu \mathrm{g} / \mathrm{ml}$ pepstatin to give a protein concentration of $10 \mathrm{mg}$ protein $/ \mathrm{ml}$ and was solubilized with $0.5 \mathrm{mg} / \mathrm{mg}$ protein of sodium cholate for 
$15 \mathrm{~min}$. The supernatant obtained by ultracentrifugation was diluted with 4 volumes of a solution containing $1 \mathrm{~mm}$ EDTA, $1 \mu \mathrm{M}$ FAD, $1 \mu \mathrm{M}$ FMN, $0.5 \%$ sodium cholate, and the diluted solution was applied to a column of DE52 equilibrated with $20 \mathrm{~mm}$ potassium phosphate buffer, $\mathrm{pH} 7.2$, containing $1 \mathrm{~mm}$ EDTA, $1 \mu \mathrm{M}$ FAD, $1 \mu \mathrm{M}$ FMN, and $0.5 \%$ sodium cholate (Buffer B). The fraction containing $\mathrm{P} 450$ reductase was eluted with a concentration gradient of $\mathrm{KCl}$ from 0 to $0.35 \mathrm{M}$ in Buffer B. The eluted P450 reductase fraction was concentrated with Amicon Ultrafiltration and was applied to a column of $2^{\prime} 5^{\prime}$-ADP Sepharose 4B equilibrated with Buffer B, before being eluted with Buffer B plus 1 mM NADP ${ }^{+}$.

Analytical Methods P450 content was determined spectrophotometrically by using the extinction coefficient difference between 450 and $490 \mathrm{~nm}$ of the reduced CO-difference spectrum $\left(91.1 \mathrm{mM}^{-1} \mathrm{~cm}^{-1}\right)$ for $\mathrm{P} 450 .{ }^{18)}$ The proteins were measured by the method of Lowry et al. ${ }^{19)}$ using bovine serum albumin as the standard.

Determination of the Enzyme Activity of F1 and F2 The activity of $\mathrm{P} 450$ reductase in F1 or F2 was determined by the NADPH-cytochrome $c$ reductase activity, and 1.0 unit was defined as the activity required to reduce $1.0 \mu \mathrm{mol}$ of cytochrome $c$ per minute. The lanosterol 14-demethylase activity of F1 or F2 was assayed according to our previous method. ${ }^{16,20)}$ The reaction mixture $(1.0 \mathrm{ml})$ contained $\mathrm{F} 1$ or F2 corresponding to $0.01 \mathrm{nmol}$ CYP51 and 0.24 unit of the reductase, $15 \mathrm{nmol}$ lanosterol dispersed with $0.04 \mathrm{mg}$ of dilauroylphosphatidylcholine (DLPC), $80 \mathrm{~mm}$ potassium phosphate buffer, $\mathrm{pH} 7.5$ containing $0.05 \%$ sodium cholate, and $0.15 \mathrm{~mm}$ NADPH with its generator (glucose 6-phosphate and glucose-6-phosphate dehydrogenase). The reaction was carried out aerobically at $30^{\circ} \mathrm{C}$ for $15-20 \mathrm{~min}$. The reaction products were extracted and analyzed with GLC as described previously, and lanosterol 14-demethylase activity was calculated from the gas-chromatogram as described elsewhere. ${ }^{19)}$

Enzymatic Reduction of $\mathbf{P 4 5 0}$ in F1 or F2 The reaction mixture (final volume: $2.0 \mathrm{ml}$ ) contained F1 or F2 corresponding to $0.15 \mathrm{nmol}$ of CYP51, $24 \mathrm{nmol}$ of lanosterol dispersed with $0.06 \mathrm{mg}$ of DLPC micelles, $0.05 \%$ sodium cholate, and $80 \mathrm{~mm}$ potassium phosphate buffer, $\mathrm{pH} 7.5$, together with an oxygen-removing system (glucose, glucose oxidase, and catalase). The above reaction mixture was placed in a spectrophotometer cuvette and bubbled with $\mathrm{CO}$. Then, the reaction was started by the addition of $150 \mu \mathrm{M}$ NADPH. The increase in absorbance at $448 \mathrm{~nm}$, indicating the formation of the reduced CO complex of P450, was recorded. The rapid phase of the $\mathrm{P} 450$ reduction was analyzed by stopped flow photometry according to the following procedure. Two solutions were prepared. Solution A contained F1 or F2 corresponding to $0.6 \mathrm{nmol}$ of CYP51 and $47 \mathrm{nmol}$ of lanosterol dispersed with $0.1 \mathrm{mg}$ of DLPC micelles in $3.0 \mathrm{ml}$ of $0.05 \%$ sodium cholate containing $80 \mathrm{~mm}$ potassium phosphate buffer, $\mathrm{pH} 7.5$. Solution B was $1.65 \mathrm{~mm}$ NADPH. Solution A was saturated with $\mathrm{CO}$ before the start of the reaction, and the reaction was started by mixing 10 volumes of solution A and one volume of B solution in a reaction chamber of a SX20 Stopped-Flow apparatus (Applied Photophysics, U.K.). The reduction of P450 in F1 or F2 was recorded as the increase in absorbance at $448 \mathrm{~nm}$. Data were obtained from five runs, and their average was recorded.

\section{RESULTS AND DISCUSSION}

The Expression of F1 and F2 in the Membrane Fraction of $\boldsymbol{E}$. coli and Their Purification Both F1 and F2 were expressed in E. coli cells and recovered in the membrane fraction of the cells. No substantial difference was observed between their expression levels, which were 60 to 200 nmol P450 per liter of culture and 0.15 to $0.4 \mathrm{nmol} \mathrm{P} 450$ per $\mathrm{mg}$ of membrane proteins. The NADPH-cytochrome $c$ reductase activity, which might have been due to the $\mathrm{P} 450$ reductase domain of $\mathrm{F} 1$ or $\mathrm{F} 2$, was $4.1-5.8 \mathrm{unit} / \mathrm{mg}$ protein. The expressed F1 and F2 in the E. coli membrane displayed a lanosterol 14-demethylase activity of $0.85-0.92 \mathrm{nmol} /$ $\mathrm{min} / \mathrm{nmol} \mathrm{P450}$. These facts indicate that both F1 and F2 are expressed in E. coli as active lanosterol 14-demethylase. The difference between fused F1 and fused F2 was the amino acid sequences used for the linker region between the N-terminal modified CYP51 (yCYP51m) and truncated P450 reductase. These amino acid sequences were chosen after reference to the amino acid sequences of the binding region between the CYP51 and P450 reductase segments in CYP102A. The amino acid sequence of the linker region of the fused F1 protein was S-T for the 463rd and 464th amino acid residues in CYP102A, which was used in many recombinant fusion proteins of mammalian P450.,6-8,10) The sequence of the fused F2 protein was S-T-E-Q-S-A-K-K-V-RK-K-A for the 463rd to 475th amino acid residues of CYP102A, and the N-terminal region of $\mathrm{P} 450$ reductase in fused F2 was more truncated than that of the $\mathrm{P} 450$ reductase in fused $\mathrm{F} 1$.

The F1 and F2 expressed in the membrane fraction of $E$. coli were solubilized by Emulgen 913 treatment and purified by the method described in Materials and Methods. The purified preparations of F1 and F2 were obtained with a high recovery (25 to $53 \%$ from the membrane fraction), and typical P450 contents of the purified F1 and F2 preparations were $5.5 \mathrm{nmol} / \mathrm{mg}$ protein and $6.3 \mathrm{nmol} / \mathrm{mg}$ protein, respectively. The purified preparations of F1 and F2 displayed a single protein band corresponding to a molecular weight of about $130 \mathrm{~K}$ in SDS-PAGE (Fig. 2). The molecular weights of the $\mathrm{F} 1$ and F2 preparations were consistent with their theoretical values, indicating that F1 and F2 are fusion proteins containing $y C Y P 51 \mathrm{~m}$ combined with $\mathrm{P} 450$ reductase.

Spectral Properties of Purified F1 and F2 Figure 3 shows the absorption spectra of the oxidized form, reduced form, and reduced-CO complex of the purified F1 and F2 preparations. The absorption spectra of the oxidized forms of

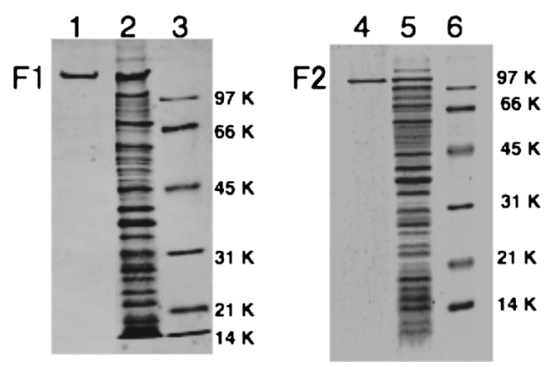

Fig. 2. SDS-Polyacrylamide Gel Electrophoresis of F1 and F2

Lanes 1 and 4 represent purified preparations of F1 and F2, respectively. Lanes 2 and 5 are membrane fractions expressing F1 and F2, respectively. Lanes 3 and 6 are standard proteins. The amounts of protein loaded for the purified preparations and the membrane fractions were $0.5 \mu \mathrm{g}$ and $10 \mu \mathrm{g}$, respectively. 

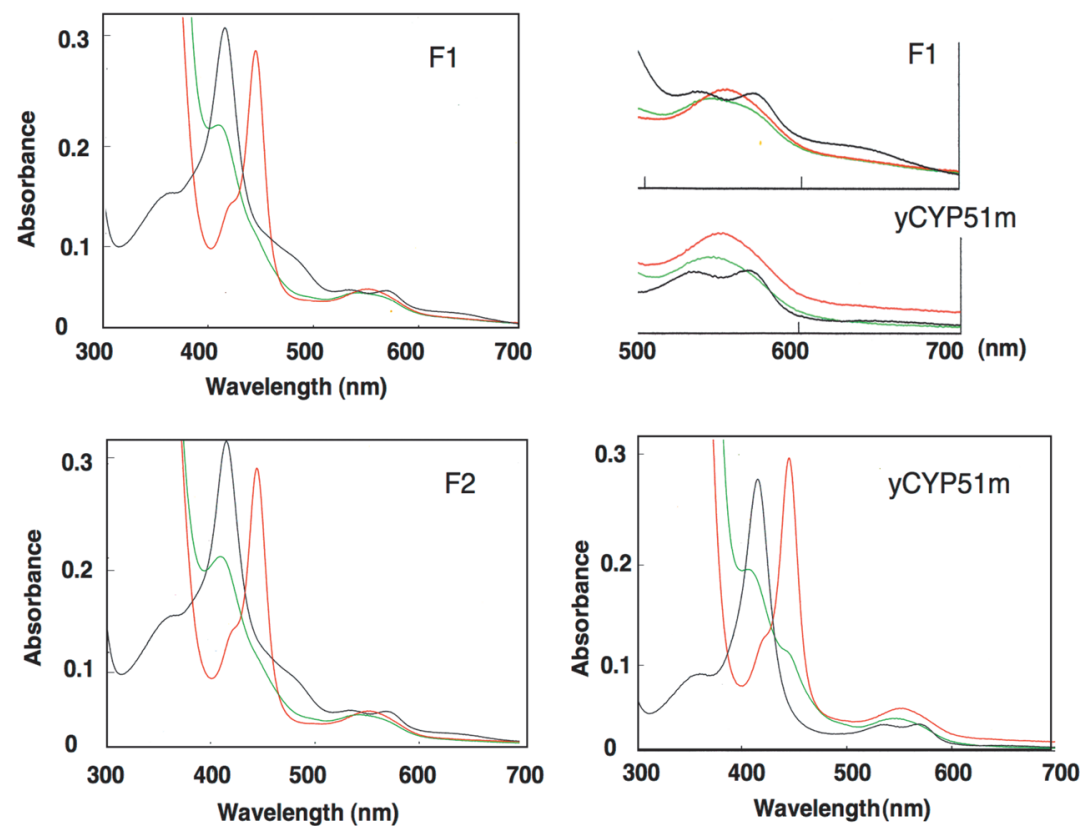

Fig. 3. The Absorption Spectra of the Purified Preparations of F1, F2, and yCYP51m

The red, green, and black lines of each panel represent oxidized, reduced, and reduced $\mathrm{CO}$ complex, respectively. The reduction was carried out by the addition of $\mathrm{Na}_{2} \mathrm{~S}_{2} \mathrm{O}_{4}$. Magnified spectra at the $500-700 \mathrm{~nm}$ region are shown for F1 and yCYP51m. The concentration of each preparation was $2.8 \mathrm{nmol} \mathrm{P} 450 / \mathrm{ml}$.

F1 and F2 shows the characteristics of low spin P450 with absorption peaks at 417,535 , and $570 \mathrm{~nm}$. These spectral characteristics are similar to those of oxidized yCYP51m. However, three critical differences were observed between the fusion proteins and yCYP5 $1 \mathrm{~m}$. The oxidized forms of F1 and F2 had a shoulder at around $480 \mathrm{~nm}$, which might have been due to the absorption bands of the FAD and FMN of the P450 reductase. The intensity of the Soret peaks $(417 \mathrm{~nm})$ of the oxidized forms of F1 and F2 were higher than that of their reduced-CO complex, whereas the Soret peak of oxidized yCYP51m was somewhat lower than that of the reduced CO-complex. This difference might also be due to the influence of the absorption of FAD and FMN in this region. The two differences have been found in many P450 and P450 reductase fusion proteins. ${ }^{2,11,21,22)}$ The absorption spectra of oxidized F1 and F2 showed a broad absorption peak at around $650 \mathrm{~nm}$, and this absorption band was not observed in the oxidized yCYP51m. A broad absorption band at around $650 \mathrm{~nm}$ is characteristic of oxidized high spin P450. However, the Soret bands of F1 and F2 indicated that they were in the low-spin state in the oxidized form. It is known that the semiquinone form of the flavin group of flavoproteins shows a weak absorption band around 580 to $650 \mathrm{~nm}$. Therefore, the flavin group of F1 and F2 may be in a partially semiquinone state. However, this problem has not yet been clarified.

CYP51 is the target of azole antifungal agents such as fluconazole and ketoconazole. ${ }^{23)}$ Azole compounds inhibit lanosterol 14-demethylase activity by binding to the active site of CYP51. ${ }^{24)}$ Ketoconazole binds quantitatively to F1 and F2 as well as yCYP51m causing a spectral change that is known as an index of the formation of the azole complex of CYP51 ${ }^{24)}$ (data not shown). This indicates that the heme environments of F1 and F2 are the same as those of yCYP51m.

The spectral characteristics of the reduced form and the reduced-CO complex of F1 and F2 were almost identical to
Table 1. A Comparison of Kinetic Parameter of F1, F2, and yCYP51m

\begin{tabular}{cccc}
\hline \hline & $K_{\mathrm{m}}(\mu \mathrm{M})$ & $\begin{array}{c}V_{\max }(\mathrm{nmol} / \mathrm{min} \\
/ \mathrm{nmol} \mathrm{P450)}\end{array}$ & $V_{\max } / K_{\mathrm{m}}$ \\
\hline $\mathrm{F} 1$ & 4.0 & 5.70 & 1.43 \\
$\mathrm{~F} 2$ & 4.4 & 5.0 & 1.14 \\
yCYP51m & 5.0 & 5.26 & 1.05 \\
\hline
\end{tabular}

Lanosterol 14-demethylase activity was determined as described in Materials and Methods by using 5 to $45 \mathrm{nmol}$ of lanosterol as the substrate. Values are averages of three independent measurements.

those of yCYP51m.

Catalytic Properties of Purified F1 and F2 Purified preparations of F1 and F2 converted lanosterol to the 14demethylated product 4,4-dimethylcholesta-8,14,24-trien-3$\mathrm{ol}$ as occurred in the case of a system consisting of purified preparations of yCYP51m and P450 reductase. This suggests that F1 and F2 can catalyze the 14-demethylation process, which consists of three successive monooxygenations. Next, the lanosterol 14-demethylase activities of F1 and F2 were compared with that of the system containing purified yCYP51m and P450 reductase under the conditions described in Materials and Methods. The activities of F1 and F2 obtained with $0.034 \mathrm{nmol}$ of P450 per assay were 4.62 and $4.31 \mathrm{nmol} / \mathrm{min} / \mathrm{nmol} \mathrm{P} 450$, whereas the activity of the reconstituted system using the same amount of purified yCYP $51 \mathrm{~m}$ and $\mathrm{P} 450$ reductase was $3.17 \mathrm{nmol} / \mathrm{min} / \mathrm{nmol}$ P450. As shown in Table 1, the kinetic parameters of F1 and F2 were comparable to those of the system containing purified yCYP51m and the purified P450 reductase from S. cerevisiae. These results indicate that the artificial fused enzymes have comparable activity to the reconstituted system. In other words, the fusion proteins F1 and F2 are self-sufficient lanosterol 14-demethylases that are able to catalyze three successive monooxygenations as is naturally-occurring CYP51.

A possible advantage of a self-sufficient $\mathrm{P} 450$ monooxyge- 
Table 2. The Effects of the CYP51 Amount on the Specific Activity of Lanosterol 14-Demethylase of the Fused Enzyme and a Reconstituted System Containing yCYP51m and Purified P450 Reductase

\begin{tabular}{|c|c|c|c|}
\hline & \multicolumn{3}{|c|}{ Activity (nmol/min/nmol P450) } \\
\hline & $0.02 \mathrm{nmol} \mathrm{P} 450$ & $0.01 \mathrm{nmol} \mathrm{P} 450$ & 0.004 nmol P450 \\
\hline $\mathrm{F} 1$ & $3.63(100 \%)$ & $2.89(80 \%)$ & $1.0 \quad(28 \%)$ \\
\hline $\mathrm{F} 2$ & $2.47(100 \%)$ & $1.80(73 \%)$ & $1.25(51 \%)$ \\
\hline $\begin{array}{l}\text { Reconstituted } \\
\text { system }\end{array}$ & $2.38(100 \%)$ & $1.10(46 \%)$ & $0.50(21 \%)$ \\
\hline
\end{tabular}

The amount of CYP51 was varied as shown above by using the same volume of the reaction mixture described in Materials and Methods. The amount of $\mathrm{P} 450$ reductase in the reconstituted system was 24 units/nmol P450 since the reductase activity induced by $0.01 \mathrm{nmol}$ of the fused enzyme was 0.24 units, as described in Materials and Methods. Values are representative ones obtained in one of the triplicate independent experiments.

nase might be effective intramolecular electron transfer from $\mathrm{P} 450$ reductase to $\mathrm{P} 450$. However, there is a possibility that the activity of F1 and F2 is dependent on intermolecular electron transfer from the P450 reductase domain to the CYP51 domain between different molecules. The specific activity of the 14-demethylase per CYP51 might not be affected by enzyme dilution if the activity is supported by intramolecular electron transfer. On the other hand, the specific activity of the same reaction might be decreased by enzyme dilution if the activity is dependent on intermolecular electron transfer between P450 reductase and CYP51 in separate molecules. Table 2 summarizes the effects of enzyme dilution on the specific activity of lanosterol 14-demethylation by $\mathrm{F} 1, \mathrm{~F} 2$, and the system containing purified yCYP51m and $\mathrm{P} 450$ reductase. Two and four times dilution of yCYP51m in the reaction mixture of the system, whose activity was dependent on the intermolecular electron transfer between P450 reductase and CYP51, reduced the specific activity per CYP51 to $46 \%$ and $21 \%$, respectively (Table 2). Although the specific activities of F1 and F2 were also decreased by dilution of the enzyme in the reaction mixture, the decrease in the specific activity was small compared with that of the reconstituted system (Table 2). These findings indicate that intramolecular electron transfer from P450 reductase to CYP51 occurs in F1 and F2, although a part of their activity might be dependent on electron transfer between P450 reductase and CYP51 in separate molecules. Similar observations have been reported for other artificial fusion proteins consisting of mammalian P450 and P450 reductase. ${ }^{6,10,11,25)}$

Effective electron transfer between P450 reductase and P450 existing in different molecules of a fusion monooxygenase could occur if the two molecules are dimeric partners, and this type of electron transfer could not be discriminated from intramolecular transfer if the dissociation constant of the dimer was very small. Such intermolecular electron transfer has been reported for naturally-occurring bacterial fusion P450 (CYP102A1) catalyzing fatty acid hydroxylation. ${ }^{26,27)}$ Accordingly, the effects of dilution on the specific activities of F1 and F2 (Table 2) can not be taken as confirmation of the occurrence of intramolecular electron transfer between the P450 reductase and CYP51 domains of these fusion enzymes.

The lanosterol 14-demethylation catalyzed by the reconstituted system containing yCYP51m and P450 reductase showed considerable uncoupling. For example, the amount of hydrogen peroxide formed during the demethylation reaction with the reconstituted system was about twice that of the demethylated metabolite of lanosterol (data not shown). Although they were expected to reduce uncoupling through an improvement in electron transport from P450 reductase to P450 in the fused enzyme, no significant reduction in hydrogen peroxide production was observed in the demethylation reactions of $\mathrm{F} 1$ and $\mathrm{F} 2$.

Kinetics of the Reduction Rate of Fused CYP51 The efficiency of electron transfer from P450 reductase to CYP51 in the fusion proteins F1 and F2 was determined spectrophotometrically by increasing the absorbance at $448 \mathrm{~nm}$ by the production of the reduced CO-complex of CYP51. As shown in Fig. 4A, about $75 \%$ of $\mathrm{P} 450$ was converted to the reduced CO-complex within a few seconds of the addition of NADPH both for F1 or F2, whereas less than $50 \%$ of yCYP $51 \mathrm{~m}$ was reduced in the reconstituted system containing the same amounts of CYP51 and P450 reductase. This observation indicates that the electron transfer from P450 reductase to CYP51 in the fusion proteins was significantly faster than that in the reconstituted system.

To obtain more precise data regarding the electron transfer from P450 reductase to CYP51, the initial rate of CYP51 reduction was analyzed using a spectrophotometer equipped with stopped flow apparatus (Fig. 4B). The initial rate of reduction of the fused enzyme without lanosterol was less than one fiftieth of that shown in Fig. 4B (data not shown). This indicates that the observed rate of CYP51 reduction was coupled with the catalytic cycle of lanosterol demethylation. The reduction of CYP51 both in the fused enzyme and the reconstituted system was biphasic and consisted of an initial fast phase followed by a slow phase. Therefore, the rate constants for the fast phase were corrected with the rate constants of the slow phase. The first-order rate constants of CYP51 reduction thus calculated from the data shown in Fig. 4B were $0.62 \mathrm{~s}^{-1}, 3.0 \mathrm{~s}^{-1}$, and $0.90 \mathrm{~s}^{-1}$, respectively, for the reconstituted system, F1, and F2. These results indicate that the electron transfer from P450 reductase to CYP51 in the artificial fused enzyme was faster than that in the reconstituted system especially for $\mathrm{F} 1$.

In these experiments, the rate of CYP51 reduction was determined by the rate of reduced CO-complex formation, which represented the rate of introduction of the first electron into the ferric P450-substerate complex. P450-catalyzed monooxygenation requires additional transfer of a second electron from P450 reductase to the oxy-ferrous intermediate formed by the reduction reaction involving the first electron, but the rate of this electron transfer could not be determined by the conventional methods available in our laboratory. Since it is thought that the rate-limiting step of P450-catalyzed monooxygenation is the transfer of the second electron to the oxy-ferrous intermediate, the results shown in Fig. 4 can not be taken as evidence that construction of the fused enzyme improves the catalytic ability of CYP51 by enhancing electron transfer from P450 reductase to P450.

Taken together, it can be concluded that self-sufficient lanosterol 14-demethylase fused enzymes consisting of $S$. cerevisiae CYP51 and S. cerevisiae P450 reductase were successfully constructed. The two artificial enzymes, named F1 and $\mathrm{F} 2$, expressed in E. coli cells showed essentially the same catalytic properties as natural CYP51. The results of this 
(A)

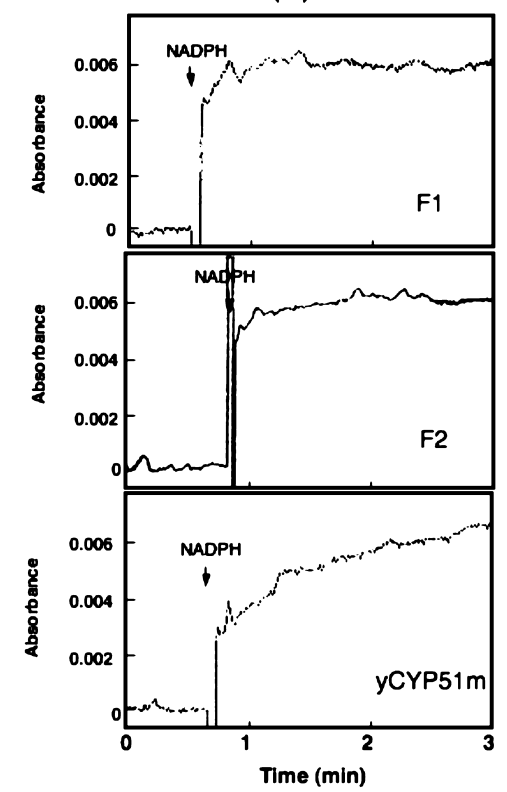

(B)
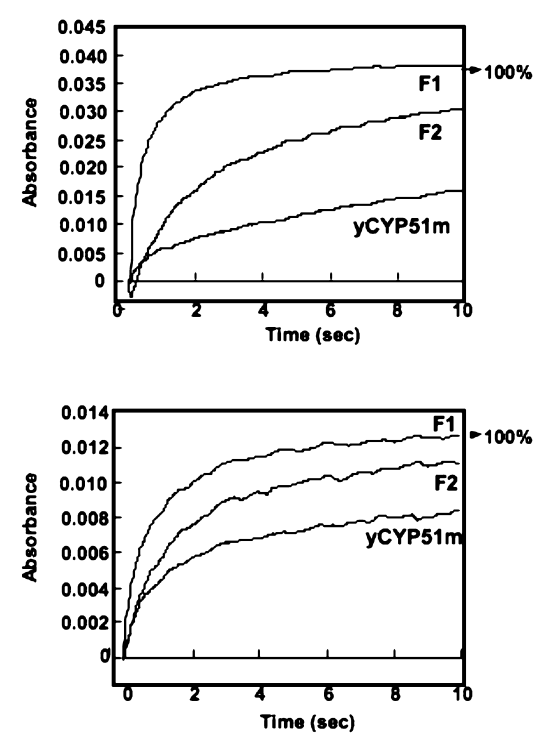

Fig. 4. Time Traces of the Enzymatic Reduction of the F1, F2, and yCYP51m Preparations

The traces shown in (A) were measured by a conventional spectrophotometer. A reaction mixture containing lanosterol (see Materials and Methods) was placed in a spectrophotometer cuvette and bubbled with $\mathrm{CO}$ gas. The absorbance at $448 \mathrm{~nm}$ of this mixture was recorded as the baseline, and NADPH solution was added to the reaction mixture. The increase in absorbance at $448 \mathrm{~nm}$ was recorded after mixing. The traces shown in (B) were obtained using a stopped-flow instrument. The conditions of this experiment were described in Materials and Methods. The label "100\%" in (B) indicates the absorbance expected for the full reduction of P450 calculated from the amount of P450 in the reaction mixture.

work provide concrete evidence that self-sufficient $\mathrm{C}-\mathrm{C}$ bond cleaving P450 monooxygenases that catalyze three successive reactions can be constructed by joining CYP51 and P450 reductase together. Although the fused enzymes only improved the catalytic activity of the enzyme by a small extent, the present results may provide hints for constructing a more efficient self-sufficient sterol 14-demethylase P450 through refinement of the molecular design of the fused protein. In addition, this is the first example of the purified preparation of an artificial self-sufficient P450 monooxygenase that catalyzes the oxidative cleavage of a $\mathrm{C}-\mathrm{C}$ bond via three successive monooxygenations.

Acknowledgments The authors wish to express their sincere thanks to Dr. M. Ikeguchi of Soka University for his kind and excellent advice and discussion concerning the kinetic analysis of P450 reduction with a SX20 stopped-flow apparatus.

\section{REFERENCES}

1) Omura T., "Cytochrome P-450," 2nd ed., ed. by Omura T., Ishimura Y., Fujii-Kuriyama Y., Kodansha, Tokyo, 1993, pp. 1-15.

2) Narhi L. O., Fulco A. J., J. Biol. Chem., 261, 7160-7169 (1986).

3) Warman A. J., Roitel O., Neeli R., Girvan H. M., Seward H. E., Murray S. A., McLean K. J., Joyce M. G., Toogood H., Holt R. A., Leys D., Scrutton N. S., Munro A. W., Biochem. Soc. Trans., 33, 747-753 (2005).

4) Shet M. S, Fisher C. W., Holmans P. L., Estabrook R. W., Proc. Natl. Acad. Sci. U.S.A., 90, 11748-11752 (1993).

5) Sakaki T., Kominami S., Takemori S., Ohkawa H., Akiyoshi-Shibata M., Yabusaki Y., Biochemistry, 33, 4933-4939 (1994).

6) Shet M. S., Fisher C. W., Arlotto M. P., Shackleton C. H., Holmans P. L., Martin-Wixtrom C. A., Saeki Y., Estabrook R. W., Arch. Biochem. Biophys., 311, 402-417 (1994).

7) Shet M. S., Fisher C. W., Holmans P. L., Estabrook R. W., Arch.
Biochem. Biophys., 330, 199-208 (1996).

8) Chun Y. J., Shimada T., Guengerich F. P., Arch. Biochem. Biophys., 330, 48-58 (1996)

9) Hara M., Miyake J., Asada Y., Ohkawa H., Biosci. Biotechnol. Biochem., 63, 21-28 (1999).

10) Helvig C., Capdevila J. H., Biochemistry, 39, 5196-5205 (2000).

11) Deeni Y. Y., Paine M. J., Ayrton A. D., Clarke S. E., Chenery R., Wolf C. R., Arch. Biochem. Biophys., 396, 16-24 (2001).

12) Dodhia V. R., Fantuzzi A., Gilardi G., J. Biol. Inorg. Chem., 11, $903-$ 916 (2006).

13) Yoshida Y., "Cytochrome P-450," 2nd ed., ed. by Omura T., Ishimura Y., Fujii-Kuriyama Y., Kodansha, Tokyo, 1993, pp. 93-100.

14) Yoshida Y., Aoyama Y., "Regulation of Heme Protein Synthesis," ed. by Fujita H., AlphaMed Press, Dayton, 1994, pp. 75-88.

15) Jackson C. J., Lamb D. C., Marczylo T. H., Warrilow A. G. S., Manning N. J., Lowe D. J., Kelly D. E., Kelly S. L., J. Biol. Chem., 277, 46959-46965 (2002).

16) Nitahara Y., Aoyama Y., Horiuchi T., Noshiro M., Yoshida Y., J. Biochem. (Tokyo), 126, 927-933 (1999).

17) Aoyama Y., Yoshida Y., Sato R., J. Biol. Chem., 259, 1661-1666 (1984).

18) Omura T., Sato R., J. Biol. Chem., 239, 2370-2378 (1964).

19) Lowry O. H., Rosebrough N. J., Farr A. L., Randall R. J., J. Biol. Chem., 193, 265-275 (1951).

20) Yoshida Y., Aoyama Y., J. Biol. Chem., 259, 1655-1660 (1984).

21) Gustafsson M. C. U., Roitel O., Marshall K. R., Noble M. A., Chapman S. K., Pessegueiro A., Fulco A. J., Cheesman M. R., Wachenfeldt C. von, Munro A. W., Biochemistry, 43, 5474-5487 (2004).

22) Dodhia V. R., Fantuzzi A., Gilardi G., J. Biol. Inorg. Chem., 11, $903-$ 916 (2006).

23) Vanden Bossche H., Marichal P., Gorrens J., Geerts H., Janssen P. A., "Antifungal Drugs," ed. by St. Georgiev, V. 544, The New York Academy of Science, New York, 1988, pp. 191-207.

24) Yoshida Y., Aoyama Y., Biochem. Pharmacol., 36, 229-235 (1987).

25) Harlow G. R., Halpert J. R., Arch. Biochem. Biophys., 326, 85-92 (1996).

26) Black S. D., Martin S. T., Biochemistry, 33, 12056-12062 (1994).

27) Neelia R., Girvana H. M., Lawrenceb A., Warrenb M. J., Leysc D., Scruttonc N. S., Munro A. W., FEBS Lett., 579, 5582-5588 (2005). 